\title{
On the relationship between trust, transparency, and surveillance
}

\author{
Lora Anne Viola and Paweł Laidler
}

\section{Introduction}

Surveillance has become a defining characteristic of twenty-first-century society. Although surveillance, broadly understood as a set of data collection and information processing practices (Lyon 2015), has ancient roots, new information technologies and the advent of big data have created conditions for the pervasive, penetrating, and highly consequential role of surveillance in the everyday lives of individuals, corporations, and governments, leading to what has been called our "surveillance society" (Marx 1985; Gandy 1989; Lyon 1994, 2001, 2004) or, more recently, a "culture of surveillance" (Lyon 2018). While new technologies and big data have enabled both a quantitative and qualitative shift in surveillance, these changes have been accompanied by a range of social, political, cultural, and economic processes that have made surveillance practices appear useful and even necessary. Surveillance appears not as a singular, top-down oppressive force, but rather as something done both to and by us in our everyday activities. On the one hand, surveillance technologies are officially legitimized by the state as tools for enhancing public safety and security. Especially since 9/11 and the so-called "war on terror," the state has enhanced its surveillance powers to enable law enforcement and intelligence agencies to collect and use data in domestic policing and counter-terrorism cases (Wood, Konvitz, and Ball 2003). From CCTV (see e.g., Norris and Armstrong 1999) to bodycams (see e.g., Lippert and Newell 2016), to bulk data collection (Ferguson 2017), the surveillance state is omnipresent (Greenwald 2014; Harris 2011; Gellman 2020; Keller 2017). On the other hand, individuals regularly and more-or-less voluntarily provide massive amounts of private data to states and corporations through our use of smartphones, social media platforms, and other internet-based services (Harcourt 2015; Lewis 2017). This personal data has now become the raw material in the process of data commodification and behavior modification that drives profits in what Shoshana Zuboff has called "surveillance capitalism" (Zuboff 2019). 
Even though surveillance is normalized through its ubiquitous presence, growing awareness of the dangers that pervasive state and corporate surveillance pose to freedom, equality, and other rights has also called forth critique and resistance (Lyon 2007). The surveillance studies literature has documented and theorized the ways in which surveillance can reduce liberty, amplify (asymmetric) power, and be a technique of governmentality used to administer, manage, sort, and distribute (Lyon 2003; Richards 2013; Barocas and Selbst 2016). Using arguments of national security and public safety, governments have been expanding surveillance powers and, with them, the potential for violating rights and freedoms (Monahan 2006, 2010; Theoharis 2011; Glennon 2015; Lester 2015;). Furthermore, recent feminist theory and critical race scholarship have begun to investigate the ways in which surveillance practices and technologies are embedded in and further normalize existing systemic inequalities based on race, gender, sexuality, and class (see, e.g., the contributions in Dubrofsky and Magnet 2015 and those in Koskela 2012; Browne 2015; Van der Meulen and Heynen 2016; Selod 2018). Surveillance thus not only presents a threat to individual freedoms, civil liberties, and privacy rights but can also reinforce, reproduce, and create structural inequalities.

Recent events have further exposed the ways in which surveillance is inextricably linked to processes of social ordering and social control. Three contemporary episodes, in particular, have raised public awareness of the dangers and risks of surveillance: the rise of the national security surveillance state in the aftermath of 9/11, especially the secret practices revealed by Edward Snowden; ${ }^{1}$ the rise of big tech companies and social media platforms that sell data without consent or regard to privacy rights, especially brought to public attention through the Facebook-Cambridge Analytica data scandal; ${ }^{2}$ and, most recently, the COVID-19 pandemic, which has not only introduced a range of new surveillance practices largely accepted because of the public health crisis but has also accelerated the digitization of society and the concomitant expansion of digital surveillance tools in the workplace, schools, and in homes (see Lyon this volume; French and Monahan 2020). One of the main features of contemporary surveillance revealed through these episodes is its secrecy, which makes it difficult, or almost impossible, for citizens to understand the scope, purposes, and effects of surveillance. Furthermore, the asymmetric power and knowledge relationship between the institutions imposing surveillance and the subjects being surveilled gives rise to relations of domination and limits the instruments of accountability available to citizens. Through occasional high-profile scandals, usually thanks to disclosures made by whistleblowers or the press, societies gain knowledge about programs used to collect, store, and process enormous amounts of personal data (Greenwald 2014; Snowden 2019; Stanger 2019). These disclosures, on the one hand, erode trust in institutions and, on the other hand, fuel calls for reforms and remedies, usually centering on privacy protections and greater transparency. 
This book critically assesses one of the most common narratives used to encapsulate current debates regarding surveillance. According to this narrative, greater transparency is one of the most promising remedies for avoiding the negative effects of surveillance on liberty and, at the same time, for restoring the public trust in institutions that is at once necessary for good governance but that has eroded as the details of surveillance practices have become known (e.g., Schneier 2013). It is commonly asserted, for example, that excessive surveillance undermines citizens' trust in governments and businesses and that the loss of trust is socially damaging - something that needs to be avoided (Sullivan 2016). Transparency, meanwhile, has become a mobilizing idea for resisting or overcoming the negative political, social, and economic consequences of surveillance (e.g., Feeney 2017). Harding (2018), for example, argues that the rise of the surveillance society has been enabled by a collapse of democratic oversight and transparency. Dominant in both the scholarly literature and public debate is the conviction that improved transparency can promote better-informed decisions and greater oversight, and that transparency can restore relations of trust damaged by the secrecy of surveillance and the potential abuse that secrecy makes possible (Peters 2013).

The contributions to this volume challenge this conventional narrative by critically investigating the theoretical and empirical relationships between surveillance, trust, and transparency. While trust, transparency, and surveillance have each been studied extensively on their own, their dynamic interaction has received little sustained attention. Moreover, within the context of surveillance the positive relationship between trust and transparency is often taken to be self-evident. Studying trust and transparency in the context of surveillance is particularly helpful in order to question established (usually positively laden) notions of these concepts and to think critically about the conditions under which trust and transparency have the effects usually ascribed to them. This book starts from the observation that an unreflective belief in the virtues of trust and transparency obscures more complex dynamics and runs the risk of promoting not only simplistic but perhaps also counterproductive proposals for remedying the dangers to liberty that accompany surveillance.

Accordingly, the contributions assembled here seek to shed light on urgent questions, such as: under what conditions is more transparency necessary to prevent the negative consequences of surveillance practices? Is transparency of contemporary surveillance practices possible at all? Under what conditions do what kinds of transparency promote accountability and prevent oppression, and when does transparency lead to further obfuscation and concealment? When does transparency help to equalize power relations and when does it serve to entrench inequalities? When and under what conditions does trust facilitate the negative consequences of surveillance practices, and when does distrust need to be fostered? How can (dis)trust be a means of dealing with power asymmetries and of promoting 
democratic oversight? How do trust and transparency limit or enable the expansion of surveillance practices? What are the legal tools that legitimize broad state/corporate surveillance with little oversight? How do trust and transparency affect democracy and the rule of law, and specifically, what opportunities do they present for holding powerful actors-governments and corporations - accountable?

What the studies in this book reveal are complex, ambivalent, and sometimes even contradictory pressures in the triadic relationship between transparency, trust, and surveillance. They do so by considering how each in practice is modulated by underlying power asymmetries, by socio-historical legacies, by economic structures, by cultural distinctiveness, and by institutional constraints. The approaches presented in these chapters suggest that the sources and consequences of trust and transparency can only be understood by taking into account how they are embedded and constructed in various social contexts, such as government institutions, market logics, racialized systems, and technological change.

\section{Rethinking the relationship between trust and transparency}

Contemporary responses to invasive surveillance practices are typically dominated by demands for greater protection of privacy rights (see, e.g., Solove 2011; Angwin 2014; Kuntze 2018) and calls for greater transparency on the part of government institutions and corporations that collect and use mass data. While demands for privacy protections have been critically examined elsewhere (e.g., Allen 2000; Henry 2013; Weinberg 2017), this book builds on critiques of transparency as an "unconditional virtue" in contemporary society (Bianchi 2013, 2). Transparency is often juxtaposed with surveillance and pointed to as a remedy against its dangers, as captured by phrases such as "sunshine is the best disinfectant." 3 Transparency generally refers to disclosure, defined as a process of seeing through or having access to information about the activities undertaken by others, which in turn allows oversight and legitimation (Davis and Cuillier 2014; Cain 2015). Pozen (2020, 326) notes that "commentators routinely assert or assume that transparency is indispensable to government accountability, democratic deliberation, citizen empowerment, public-spirited regulation, and public trust in the policy process." In theory, by revealing information that exposes discrepancies between rules and practice, transparency allows authority to be held accountable because exposed discrepancies can be punished (e.g., through judicial institutions), in turn providing incentives for cooperative behavior. But the emerging field of critical transparency studies (Koivisto 2019) argues that transparency is not a coherent normative ideal, nor is it a clear legal policy or governance practice (Pozen and Schudson 2018). Instead, the dynamics of transparency can only be understood in the context of specific constellations of power, interests, 
and values and thus require a sociological approach (Pozen 2020; Alloa and Thomä 2018; McCarthy and Fluck 2017). In this critical spirit, the chapters in this volume complicate the positive and even "quasi-religious significance" that is often attributed to transparency $(\operatorname{Hood} 2006,3)$.

Transparency is often approached from an epistemological standpoint as a condition that allows truth to reveal itself (Alloa and Thomä 2018, 45). Transparency is thus typically understood as a property of information (McCarthy and Fluck 2017). But this view becomes problematic to the extent that "truth" and "information" never stand alone and are not objectively accessible. As Bianchi argues, transparency can have negative consequences for accountability and cooperation because it is susceptible to the manipulation of information (Bianchi 2013, 10), rendering transparency a political accessory, a convenient "illusion" rather than an accountability mechanism (see also Roberts 2011). Building on this critique, Lora Anne Viola's chapter in this volume shows that by considering transparency as a political practice, rather than merely as the disclosure of information, we can begin to understand how transparency can come to have counter-intuitive effects, such as the legitimation, and even extension, of state surveillance powers. Similarly, Paweł Laidler in this volume discusses the political and legal relationship between secrecy and transparency in the history of US government surveillance, showing how the rhetoric of "national security" enables a cat-andmouse game between demands for secrecy vs. transparency, making a stable regime of true transparency impossible and leading, instead, to transparency "traps" that appear to offer (partial) disclosure but no true accountability. Mateusz Kolaszyński's chapter, meanwhile, shows how existing political, legal, and institutional contexts in Poland have completely stymied transparency and oversight mechanisms, rendering them too weak to guard against the use of surveillance to curtail rights.

In light of these critiques, we should be cautious about claims that transparency can rebalance power relations and exert a positive influence on cooperation and compliance. New research shows that transparency that successfully exposes the extent to which actors do not comply with rules and expectations can be corrosive of social and political order and even legitimate further noncompliance (e.g., Carnegie and Carson 2018; Curtin and Meijer 2006, 11). As O'Neill notes, transparency can foster a "culture of suspicion" (O'Neill 2002, 77), thus creating societies of control. Research shows, for example, that although many post-Communist societies, such as Poland, used exposure of former informants and surveillance collaborators as a way of enhancing public trust in new democratic institutions, such exposure, in fact, reduced public trust (Choi and David 2012). Transparency, in other words, can have chilling effects for the same reasons that surveillance does. Matthew Hall's chapter in this volume draws on political philosophy to argue that transparency makes individuals more acutely aware of the power held over them but does not help to free them from domination. 
Indeed, critical race and feminist theories have shown how transparency can become a technique of domination. Fischer (2019), for example, has shown how visibility can reinforce notions of "deviance" and thus justify state violence against trans people. Rachel Hall (2015), studying transparency practices on the traveler, theorizes the "aesthetics of transparency" as submission to surveillance. Critical race studies have shown how surveillance and transparency practices have been informed by colonialism and racial oppression that depended on policing black life under slavery (e.g., Browne 2015; Rosenthal 2018). In a similar vein, Markus Kienscherf in this volume discusses how contemporary surveillance practices in the United States have their origins in settler colonialism and its system of racialized expropriation. The idea that greater transparency can have outright oppressive effects is underscored in Shaul Duke's chapter on Israeli-Palestinian relations, which shows how imposed transparency can become a tool of social control and a weapon in societal conflicts. With a different focus, Abel Reiberg also explores the relationship between transparency and surveillant control by looking at how market incentives drive social media platforms to push users toward ever greater transparency and self-exposure.

These critiques of transparency do not amount to a wholesale rejection of the idea that transparency can bring benefits to democratic governance, but they do present a strong argument for thinking about transparency more specifically in its particular socio-cultural and political contexts. In this spirit, Thorsten Wetzling and Kilian Vieth's contribution to this volume assesses a wide range of good practice recommendations to provide a more nuanced picture of how and under what conditions specific legal safeguards and transparency mechanisms can produce more effective - rather than illusional - oversight.

One of the central justifications for demanding transparency from governments and corporations is its perceived importance for restoring trust lost through secret, nonconsensual, or invasive surveillance practices. Trust, like transparency, mostly takes on a positive normative valence in current literature (Etzioni 2010, 389; Hardin 2002a). Trust plays a pervasive role in modern social relations and is considered crucial for sustaining social cooperation and democratic governance (Cook 2001; Hardin 2002a; Cook, Hardin, and Levi 2005; Seligman 1997). Trust is seen as facilitating relations between nation states (Kydd 2000), between elected representatives and citizens (Hollyer, Rosendorff, and Vreeland 2019), between government agencies and citizens (Fung 2013), and between individuals. Surveillance practices, in turn, are seen as detrimental to public trust and corrosive of social relations that depend on trust.

Trust can broadly be defined as the belief of one actor that another actor will reciprocate cooperation rather than exploit that cooperation. The "trust giver" cooperates with the "trust receiver" in the belief that he or she will not be taken advantage of and is therefore vulnerable to and dependent on 
the reaction of the trust receiver. Trust relations can be further distinguished based on the actor level (e.g., interpersonal or institutional trust) and on the relational distance (e.g., particularized trust or generalized trust). A central feature of any trust relation is that it entails risk, a measurable degree of uncertainty about whether or not the other side will cooperate (Hardin 2002a; Kydd 2000). Beyond these basic points, however, the literature on trust is divided into understandings of trust as a rational, strategic calculus and understandings of trust as a normative, moralistic relationship based on socialization rather than strategic interaction (Nannestad 2008). The rationalist view draws on insights from game theory and Bayesian analysis and sees trust, in Hardin's (2002a) terms, as "encapsulated self-interest" or the result of the rational processing of information about which actors have reasons to act in our best interest (see also Hardin 2002a; Kydd 2000, 2007). But as others have pointed out (Rathbun 2012, 3-7), this conception reduces trust to compliance based on cost assessments. A normative view, in contrast, sees trust as based on the socialized belief that potential trustees will "do what is right" (Uslaner 2002).

The chapters in this volume that focus on trust pick up this debate and examine why a normative or sociological understanding of trust is important in our surveillance society. Fredrika Björklund, for example, argues that a rational explanation of trust fails to explain the contradiction between empirical findings that show a positive correlation between public trust in institutions and acceptance of surveillance practices, and those that show how surveillance leads to a deterioration of public trust. Sara Degli-Esposti and David Arroyo similarly argue that in order for technical systems to earn our trust, digital authentication processes need to go beyond a rational information logic to include an ethic of care built on the integrity and benevolence of the operators of such systems. These contributions go beyond game theory to think about the social contexts that promote or erode trust.

Although the conventional wisdom treats transparency as the currency of trust, there are good theoretical and empirical reasons to see trust and transparency as being in tension with one another. The logic of trust works through social beliefs that the other will cooperate and reciprocate in the absence of monitoring and punishment mechanisms, while transparency works through monitoring and punishment. Transparency aims to eliminate risk and uncertainty and to increase control, while trust is based on accepting a degree of vulnerability. In this sense, trust and transparency can serve as substitutes for one another, rather than as mutually reinforcing complements. Experimental studies on individuals, for example, show that the more trustworthy cooperation partners are perceived to be, the less monitoring is necessary. Conversely, the reliance on monitoring mechanisms, such as among employees, inhibits the creation of trust (Schweitzer, Ho, and Zhang 2018). Shaul Duke's study of pro-Palestinian human rights groups and the Israeli 
state in this volume provides an example of how transparency can inhibit trust-building and foster suspicion and hostility.

What makes trust analytically interesting from the perspective of surveillance practices is precisely that it captures willingness to cooperate even in the face of vulnerability to exploitation (Ostrom and Walker 2003). Some scholars have argued that surveillance is conducive to the creation of trust, since it allows actors to ensure that mutually agreed-upon rules of behavior are adhered to (Lombardi and Woods 2008, 723), while others have argued that trust is contrary to surveillance because surveillance is based on a logic of monitoring, whereas trust expects compliance with rules of behavior in the absence of monitoring (Cofta 2007, 20; Neyland 2006, 9). The trust literature has raised a number of important questions in this regard, including whether legal sanctions reinforce or undermine trust, whether too much trust renders the public vulnerable to government corruption or abuse, and whether distrust can be healthy to democratic governance (see, e.g., contributions in Braithwaite and Levi 1998; and in Hardin 2004). Paradoxically, too much trust can enable the very kind of exploitation and abuse that leads to its erosion, and conversely, distrust can enhance the conditions that foster cooperation and trust (Sztompka 1998; Hardin 2002b, 2004). Some studies have shown that trust in government is a crucial permissive condition for allowing the abuse of civil liberties through surveillance because they find evidence that high levels of trust in government make citizens more likely to cede their civil liberty protections and accept government surveillance practices (Davis and Silver 2003, 28-46). Other studies have shown that low political trust leads to greater political activism and involvement (Kaase 1999) or that trust is not necessary for cooperation and democratic governance at all (e.g., Cook, Hardin, and Levi 2005). These insights suggest a complex relationship between trust and distrust that the chapters by Matthew Hall and Miguelángel Verde Garrido in this volume consider in the context of surveillance. In different ways, both these chapters make a case that distrust is crucial for shoring up healthy democratic governance, promoting contestation and deliberation, and avoiding domination in a surveillance society.

\section{The contributions of this volume}

This book is intended to expose, illuminate, and go some way toward resolving the contradictions apparent in the triadic relationship between trust, transparency, and surveillance. Building on and integrating insights from existing literature, the chapters in this volume revolve around three overarching insights. First, they share a critique of "naturalistic" approaches to trust and transparency that take these concepts as having a straightforward meaning and emphasize, instead, the ways in which the meaning and implications of trust and transparency are contingent on intersubjective interactions, power relations, and institutional contexts. Second, recognizing 
the social construction of these concepts brings into sharper focus their susceptibility to relations of power, and all chapters touch on the ways in which trust and transparency can be tools of power and domination. Third, then, the chapters shed light on the conditions under which trust and transparency, shaped by power relations, technological capabilities, institutions, and socio-historical legacies, facilitate or regulate surveillance practices. Not all of the contributions address the interplay of all three core concepts, but each addresses some combination of them.

The book is divided into three parts. The chapters in Part I focus on transparency and its relation to enabling or restraining surveillance. They stress the ways in which the effects of transparency are contingent on the social and political contexts and relationships in which it is deployed. Lora Anne Viola's chapter begins this discussion by identifying and critiquing the arguments that underpin dominant claims about transparency's beneficial effects for regulating surveillance practices. She then introduces three distorting effects of transparency conditioned by a political process that takes place in the context of asymmetrical power relations and conflicting strategic interests. Through a comparative analysis of legislative reforms meant to curtail surveillance abuses in the United States, United Kingdom, and Germany, she shows how transparency can lead to the legitimation and even extension of surveillance powers, rather than their regulation. In Chapter 3, Matthew Hall similarly considers the chilling effects of transparency as it reveals, rather than regulates, the exercise of power. Considering trust and transparency from the perspective of neo-republican political theory, which emphasizes liberty as nondomination and citizen participation, Hall argues that transparency can expose the power of state surveillance but not reduce its harms. Indeed, transparency makes citizens more aware of the power held over them and thus can contribute to domination. He considers, instead, alternative forms of transparency and uses of distrust to avoid state surveillance's infringements upon liberty and to foster public deliberation about the purposes of surveillance. In Chapters 4 and 5, Shaul Duke and Markus Kienscherf pick up on the relationship between transparency and domination in the cases of IsraeliPalestinian relations and neo-colonialism in the United States, respectively. Duke analyses the relationship between imposed transparency and surveillance in the ongoing conflict between the Israeli state and Palestinians living in the West Bank. Transparency, he argues, can become a strategic tool that undermines trust, escalates conflict, and does not empower the weak. Kienscherf considers surveillance practices as central to the accumulation of capital and the formation of race, especially as these practices have been used in the process of expropriating and exploiting black labor in the United States. He argues that continuing contemporary practices of transparency, such as those that monitor workers or track welfare recipients, are part of a neocolonial logic of capital that reproduces racial divisions even under conditions of formal equality. The policy implication of these contributions 
is that transparency cannot be blindly relied upon to reduce the harms of surveillance or to restore trust.

The chapters in Part II consider the interactions of trust and transparency in specific surveillance contexts. In Chapter 6, Paweł Laidler considers the evolution of surveillance laws in the US national security state, pointing in particular to the perpetual tension between claims that security requires secrecy, on the one hand, and claims that transparency rules are required for democratic accountability, on the other. By tracing historical and contemporary US policies across the three branches of government, especially in the wake of Snowden's leaks, he argues that the United States has never been able to reach a stable coexistence between demands for secrecy and demands for transparency, as there is a constant tendency to over-correct in one direction or the other. Picking up on the tension between government demands for secrecy and citizen demands for accountability through transparency, in Chapter 7 Mateusz Kolaszyński traces the legal and institutional legacies in post-Communist Poland that have rendered efforts to restrain the surveillance powers of the state futile. Instead, he shows how institutional changes have strengthened the state's surveillance powers even in the face of counterpressures from internal (e.g., civil society) and external (e.g., EU) actors. Almost as if in reply to Laidler and Kolaszyński's concerns, in Chapter 8 Thorsten Wetzling and Kilian Vieth propose a set of concrete best practices taken from real-world examples that can make transparency work to reduce the risks of harm from state surveillance. Sharing with us their think tank expertise, this chapter brings theoretical arguments into dialogue with current policy debates to yield concrete recommendations. In Chapter 9, Abel Reiberg turns to consider the role of transparency and surveillance in social media platforms. Using the example of Facebook, he teases out the market logic by which corporations pressure users to become increasingly transparent while creating incentives for platforms and their data use to remain inscrutable. Reiberg's case study shows how transparency is used to develop "legitimate" regimes of surveillance in capitalist markets. Together, the chapters in this section shed light on the potentials (and pitfalls) of institutional change for achieving an acceptable balance between transparency and secrecy, and between trust and distrust.

The chapters in Part III turn to focus on the issue of trust and distrust by reflecting on the varied sources and types of trust, including mistrust, and their ability to reduce the harms that can be caused by surveillance. The contributions in this section argue that the causes and effects of trust beliefs are contingent rather than immutable and can only be understood as embedded in specific social and political contexts. Fredrika Björklund in Chapter 10 begins by considering the contradiction between the many empirical studies that show a positive correlation between trust in public institutions and acceptance of invasive surveillance practices and the widespread argument that invasive surveillance practices erode trust in society. She argues that 
we can go some way to resolving this contradiction by moving away from a rational understanding of trust as the result of good (or poor) performance to think instead about the shared social values and experiences that shape trust relations. By embedding trust beliefs into specific socio-cultural settings, we can better understand how trust relations change over time and space, and across different communities and issue areas. In this same vein, in Chapter 11 Sara Degli-Esposti and David Arroyo consider what trust might mean when we are increasingly dependent on machines and algorithms while having ever more limited knowledge and power to hold them accountable. In thinking about how notions of trust are affected by changing epistemological and technological standards, they argue that digital technology requires us to have mechanisms to ensure that the humans who design and operate digital systems are trustworthy. Rather than base these mechanisms on rationalinstrumental motives, they argue for the importance of generating a professional ethics of care among those who design and run digital systems. In Chapter 12, Miguelángel Verde Garrido considers the value of the public's lack of trust for generating trustworthy democratic institutions. Through case study analysis of abusive surveillance practices in the United States, Poland, and Germany, he argues for a "militant democracy" that can ensure and enhance government trustworthiness through institutions of oversight and accountability and citizen engagement. His argument highlights the role of democratic institutions in providing corrections when breaches of trust occur and describes how, through its dynamic nature, healthy distrust can restore trust and support democratic norms. The volume is rounded out with a concluding chapter by David Lyon, providing an outlook that opens the horizon to the larger issues at stake in the book. In particular, Lyon considers how human agency can be mobilized to bring forth an ethics of care and digital justice that allows the technological innovations underpinning surveillance to be used for, and not against, human flourishing.

This book grows out of two workshops, one held at the Freie Universität in Berlin in 2018 and a second at the Jagiellonian University in Krakow in 2019, as well as several conference sections and panels in 2019, through which we brought together a group of scholars from different disciplines interested in exploring the relationship between trust and transparency in the context of surveillance. Funding for our meetings and research was provided by joint grants from the German National Research Foundation (DFG, Deutsche Forschungsgemeinschaft) and the Polish National Science Center (NCN, Narodowe Centrum Nauki). ${ }^{4}$ The participants in this collaborative endeavor come from diverse fields, including surveillance studies, political science, security studies, constitutional law, sociology, and political philosophy. They bring to this volume disciplinary and interdisciplinary perspectives reflecting their academic backgrounds and also their personal expertise and different national contexts. The contributions also display a variety of research strategies, including comparative case studies, country case studies, legal analysis, 
policy analysis, and analytical political theory. The multidisciplinary and international character of the volume are key strengths that allow it to address political, legal, economic, historical, and cultural aspects of the relationship between trust, transparency, and surveillance.

This is not to say, however, that we have been able to address all the facets and aspects that deserve consideration. There is much work still to be done and many avenues for research that we have not been able to pursue here, including further work from the perspectives of gender, race, and intersectionality, research on specific technologies, and work on corporate surveillance and big data, especially as these intersect with state surveillance practices. Furthermore, the COVID-19 pandemic began just as this project reached completion, so we have not been able to address the many associated challenges for surveillance, trust, and transparency that will most certainly emerge. Fortunately, however, in the concluding chapter David Lyon reflects on the challenges of the pandemic in the context of thinking about how we can promote human flourishing and justice in an age of surveillance. Especially because of all the work that still needs to be done, and that could not be undertaken here, our hope is that this volume brings attention to the importance of thinking about the compatibilities and contradictions that arise in the interactions among trust, transparency, and surveillance, and that it sheds some light on the contingencies and complexities of these relationships.

\section{Notes}

1 In 2013, the whistleblower copied about two million classified documents, relating mostly to the operations conducted by the NSA, which revealed several secretive surveillance programs and activities, as well as the scope of data collection by the US government.

2 The scandal, first reported in 2015, involved the company Cambridge Analytica harvesting personal data from millions of Facebook users without consent and then using this data to create targeted political advertising that it sold to political campaigns. The scandal was an example of privacy breaches, the commodification of data, and the use of such data to influence democratic processes (Chen 2018).

3 This phrase, quoted often in the context of surveillance, was famously used by US Supreme Court Justice Louis Brandeis in a 1913 Harper's Weekly article entitled "What Publicity Can Do."

4 The project was titled Trust and Transparency in an Age of Surveillance: American, German, and Polish Perspectives (TATAS) led by Lora Anne Viola and Pawel Laidler, and was funded by grant numbers: DFG Project \#381384607 and NCN Project \#2016/23/G/HS5/01864.

\section{References}

Allen, Anita. 2000. "Privacy-as-Data Control: Conceptual, Practical, and Moral Limits of the Paradigm." Connecticut Law Review 32: 861-75. 
Alloa, Emmanuel, and Dieter Thomä, eds. 2018. Transparency, Society and Subjectivity: Critical Perspectives. London: Palgrave Macmillan.

Angwin, Julia. 2014. Dragnet Nation: A Quest for Privacy, Security, and Freedom in a World of Relentless Surveillance. New York: Times Books.

Barocas, Solon, and Andrew D. Selbst. 2016. "Big Data's Disparate Impact." California Law Review 104(3): 671-732.

Bianchi, Andrea. 2013. "On Power and Illusion: The Concept of Transparency in International Law." In Transparency in International Law, edited by Andrea Bianchi and Anne Peters, 1-20. Cambridge: Cambridge University Press.

Braithwaite, Valerie, and Margaret Levi. 1998. Trust and Governance. New York: Russell Sage Foundation.

Browne, Simone. 2015. Dark Matters: On the Surveillance of Blackness. Durham: Duke University Press.

Cain, Bruce. 2015. "The Transparency Paradox.” The American Interest 11(2), www. the-american-interest.com/2015/10/10/the-transparency-paradox/.

Carnegie, Allison, and Austin Carson. 2018. "The Spotlight's Harsh Glare: Rethinking Publicity and International Order." International Organization 72(3): 627-57.

Chen, Adrian. 2018. "Cambridge Analytica and Our Lives Inside the Surveillance Machine." The New Yorker. March 21, 2018, www.newyorker.com/tech/annals-oftechnology/cambridge-analytica-and-our-lives-inside-the-surveillance-machine.

Choi, Susanne Y.P., and Roman David. 2012. "Lustration Systems and Trust: Evidence from Survey Experiments in the Czech Republic, Hungary, and Poland." American Journal of Sociology 117(4): 1172-201.

Cofta, Piotr. 2007. Trust, Complexity and Control: Confidence in a Convergent World. Chichester: Wiley.

Cook, Karen. 2001. Trust in Society. New York: Russell Sage Foundation.

Cook, Karen, Russell Hardin, and Margaret Levi. 2005. Cooperation without Trust? New York: Russell Sage Foundation.

Curtin, Deirdre, and Albert Meijer. 2006. "Does Transparency Strengthen Legitimacy?" Information Polity 11(2): 109-22.

Davis, Charles N., and David Cullier. 2014. Transparency 2.0: Digital Data and Privacy in a Wired World. New York: Peter Lang Publishing.

Davis, Darren W., and Brian D. Silver. 2003. "Civil Liberties vs. Security: Public Opinion in the Context of the Terrorist Attacks on America." American Journal of Political Science 48(1): 28-46.

Dubrofsky, Rachel E., and Shoshana Magnet, eds. 2015. Feminist Surveillance Studies. Durham: Duke University Press.

Etzioni, Amitai. 2010. "Is Transparency the Best Disinfectant?" Journal of Political Philosophy 18(4): 389-404.

Feeney, Matthew. 2017. "When It Comes to Surveillance, Watch the Watchmen." The New York Times. October 23, 2017, www.nytimes.com/2017/10/23/opinion/policesurveillance.html.

Ferguson, Andrew G. 2017. The Rise of Big Data Policing: Surveillance, Race, and the Future of Law Enforcement. New York: New York University Press.

Fischer, Mia. 2019. Terrorizing Gender: Transgender Visibility and the Surveillance Practices of the U.S. Security State. Lincoln: University of Nebraska Press.

French, Martin, and Torin Monahan. 2020. "Dis-ease Surveillance: How Might Surveillance Studies Address COVID-19?” Surveillance \& Society 18(1): 1-11. 
Fung, Archon. 2013. "Infotopia: Unleashing the Democratic Power of Transparency." Politics \& Society 41(2): 183-212.

Gandy, Oscar H. 1989. "The Surveillance Society: Information Technology and Bureaucratic Social Control.” Journal of Communication 39(3): 61-76.

Gellman, Barton. 2020. Dark Mirror: Edward Snowden and the American Surveillance State. New York: Penguin Press.

Glennon, Michael J. 2015. National Security and Double Government. Oxford: Oxford University Press.

Greenwald, Glenn. 2014. No Place to Hide: Edward Snowden, the NSA, and the U.S. Surveillance State. New York: Metropolitan Books.

Hall, Rachel. 2015. The Transparent Traveler: The Performance and Culture of Airport Security. Durham: Duke University Press.

Harcourt, Bernhard E. 2015. Exposed: Desire and Disobedience in the Digital Age. Cambridge: Harvard University Press.

Hardin, Russell. 2002a. Trust and Trustworthiness. New York: Russell Sage Foundation. Hardin, Russell. 2002b. “Liberal Distrust.” European Review 10(1): 73-89.

Hardin, Russell. 2004. Distrust. New York: Russell Sage Foundation.

Harding, James M. 2018. Performance, Transparency, and the Cultures of Surveillance. Ann Arbor: Michigan University Press.

Harris, Shane. 2011. The Watchers: The Rise of America's Surveillance State. New York: Penguin Books.

Henry, Aaron. 2013. "The Perpetual Object of Regulation: Privacy as Pacification." Socialist Studies/Etudes Socialistes 9(2): 94-110.

Hollyer, James R., B. Peter Rosendorff, and James Raymond Vreeland. 2019. "Transparency, Protest and Democratic Stability." British Journal of Political Science 49(4): 1251-77.

Hood, Christopher. 2006. "Transparency in Historical Perspective." In Transparency: The Key to Better Governance?, edited by Christopher Hood and David Heald, 3-23. Oxford: Oxford University Press.

Kaase, Max. 1999. "Interpersonal Trust, Political Trust and Non-Institutionalized Political Participation in Western Europe.” West European Politics 22(3): 1-21.

Keller, William. 2017. Democracy Betrayed: The Rise of the Surveillance Security State. Berkeley: Counterpoint.

Koivisto, Ida. 2019. “Towards Critical Transparency Studies.” Res Publica 25(3): 439-43.

Koskela, Hille. 2012. "'You Shouldn't Wear that Body': The Problematic of Surveillance and Gender." In Routledge Handbook of Surveillance Studies, edited by Kirstie Ball, Kevin Haggerty and David Lyon, 49-56. Abingdon: Routledge.

Kuntze, Jan-Hendrik. 2018. The Abolishment of the Right to Privacy? The USA, Surveillance, and the Spiral Model. Baden: Nomos.

Kydd, Andrew. 2000. "Overcoming Mistrust." Rationality and Society 12(4): 397-424.

Kydd, Andrew. 2007. Trust and Mistrust in International Relations. Princeton: Princeton University Press.

Lester, Genevieve. 2015. When Should State Secrets Stay Secret? Accountability, Democratic Governance, and Intelligence. Cambridge: Cambridge University Press.

Lewis, Randolph. 2017. Under Surveillance: Being Watched in Modern America. Austin: University of Texas Press. 
Lippert, Randy K., and Bryce Clayton Newell. 2016. "Debate Introduction: The Privacy and Surveillance Implications of Police Body Cameras." Surveillance \& Society 14(1): 113-6.

Lombardi, Domenico, and Ngaire Woods. 2008. "The Politics of Influence: An Analysis of IMF Surveillance.” Review of International Political Economy 15(5): 711-39.

Lyon, David. 1994. The Electronic Eye: The Rise of the Surveillance Society. Cambridge: Polity Press/Blackwell.

Lyon, David. 2001. Surveillance Society: Monitoring Everyday Life. Buckingham: Open University Press.

Lyon, David. 2003. Surveillance as Social Sorting: Privacy, Risk and Automated Discrimination. London: Routledge.

Lyon, David. 2004. "Globalizing Surveillance: Comparative and Sociological Perspectives.” International Sociology 19(2): 135-49.

Lyon, David. 2007. Surveillance Studies: An Overview. Cambridge: Polity Press.

Lyon, David. 2015. Surveillance after Snowden. Cambridge: Polity Press.

Lyon, David. 2018. The Culture of Surveillance: Watching as a Way of Life. Cambridge: Polity Press.

Marx, Gary T. 1985. "The Surveillance Society: The Threat of 1984-Style Techniques." The Futurist 6: 21-26.

McCarthy, Daniel R., and Matthew Fluck. 2017. "The Concept of Transparency in International Relations: Towards a Critical Approach." European Journal of International Relations 23(2): 416-40.

Monahan, Torin. 2006. Surveillance and Security: Technological Politics and Power in Everyday Life. London: Routledge.

Monahan, Torin. 2010. Surveillance in the Time of Insecurity. New Brunswick: Rutgers University Press.

Nannestad, Peter. 2008. "What Have We Learned About Generalized Trust, If Anything?" Annual Review of Political Science 11: 413-36.

Neyland, Daniel. 2006. Privacy, Surveillance and Public Trust. New York: Palgrave Macmillan.

Norris, Clive, and Gary Armstrong. 1999. The Maximum Surveillance Society: The Rise of CCTV. London: Routledge.

O'Neill, Onora. 2002. A Question of Trust: The BBC Reith Lectures 2002. Cambridge: Cambridge University Press.

Ostrom, Elinor, and James Walker. 2003. "Introduction." In Trust and Reciprocity: Interdisciplinary Lessons from Experimental Research, edited by Elinor Ostrom and James Anthony Walker, 3-18. New York: Russell Sage Foundation.

Peters, Anne. 2013. "Towards Transparency as a Global Norm." In Transparency in International Law, edited by Andrea Bianchi and Anne Peters, 534-607. Cambridge: Cambridge University Press.

Pozen, David E. 2020. "Seeing Transparency More Clearly." Public Administration Review 80(2): 326-31.

Pozen, David, and Michael Schudson. 2018. “Introduction.” In Troubling Transparency: The History and Future of Freedom of Information, edited by David Pozen and Michael Schudson, 1-10. New York: Columbia University Press.

Rathbun, Brian. 2012. Trust in International Cooperation: International Security Institutions, Domestic Politics and American Multilateralism. Cambridge: Cambridge University Press. 
Richards, Neil M. 2013. "The Dangers of Surveillance." Harvard Law Review 126(7): 1934-65.

Roberts, Alasdair. 2011. "Wikileaks: The Illusion of Transparency." International Review of Administrative Science 78(2): 116-33.

Rosenthal, Caitlin. 2018. Accounting for Slavery: Masters and Management. Cambridge: Harvard University Press.

Schneier, Bruce. 2013. "The Only Way to Restore Trust in the NSA." The Atlantic. September 4, 2013, www.theatlantic.com/politics/archive/2013/09/the-only-way-torestore-trust-in-the-nsa/279314/.

Schweitzer, Maurice E., Teck-Hua Ho, and Xing Zhang. 2018. "How Monitoring Influences Trust: A Tale of Two Faces." Management Science 64(1): 253-70.

Seligman, Adam. 1997. The Problem of Trust. Princeton: Princeton University Press.

Selod, Saher. 2018. Forever Suspect: Racialized Surveillance of Muslim Americans in the War on Terror. New Brunswick: Rutgers University Press.

Snowden, Edward. 2019. Permanent Record. New York: Henry Holt.

Solove, Daniel. 2011. Nothing to Hide: The False Tradeoff Between Privacy and Security. New Haven: Yale University Press.

Stanger, Allison. 2019. Whistleblowers: Honesty in America from Washington to Trump. New Haven: Yale University Press.

Sullivan, Margaret. 2016. "Yahoo Helps the Government Read Your Emails. Just Following Orders, They Say." The Washington Post. October 6, 2016, www. washington post.com/lifestyle/style/yahoo-helps-the-government-read-youremails-just-following-orders-they-say/2016/10/05/05648894-8b01-11e6-875e2c1bfe943b66_story.html.

Sztompka, Piotr. 1998. "Trust, Distrust and Two Paradoxes of Democracy." European Journal of Social Theory 1(1): 19-32.

Theoharis, Athan G. 2011. Abuse of Power: How Cold War Surveillance and Secrecy Policy Shaped the Response to 9/11. Philadelphia: Temple University Press.

Uslaner, Eric M. 2002. The Moral Foundations of Trust. Cambridge: Cambridge University Press.

Van der Meulen, Emily, and Robert Heynen. 2016. Expanding the Gaze: Gender and the Politics of Surveillance. Toronto: University of Toronto Press.

Weinberg, Lindsay. 2017. "Rethinking Privacy: A Feminist Approach to Privacy Rights after Snowden." Westminster Papers in Communication and Culture 12(3): 5-20.

Wood, David, Eli Konvitz, and Kirstie Ball. 2003. "The Constant State of Emergency? Surveillance after 9/11." In The Intensification of Surveillance: Crime, Terror and Warfare in the Information Era, edited by Kirstie Ball and Frank Webster, 137-50. London: Pluto Press.

Zuboff, Shoshana. 2019. The Age of Surveillance Capitalism. London: Profile Books. 